\title{
Pengintegrasian Perlintasan Sebidang Dengan Alat Pemberi Isyarat Lalu Lintas (Apill)
}

\author{
Azhar Hermawan Riyanto, Bambang Drajat, \\ Uriansah Pratama, Robert Simanjuntak \\ PTDI-STTD \\ Email: azhar4@gmail.com
}

\begin{abstract}
Safety is a major factor that is considered by service users to choose the mode of transportation that will be used, both on land, sea and air. Railways is an integrated system consisting of infrastructure, facilities and human resources, as well as norms, criteria, requirements and procedures for the operation of railroad transportation. SMKP (Railway Safety Management System) is part of the overall railroad management management system in order to improve railway safety. A level crossing is a level crossing between a railroad track and a road. A prominent issue at a level crossing is the high number of traffic accidents between vehicles and trains, especially at unmanned crossings. The fact that the problem at a level crossing is always controversial, where on the one hand, the community needs shorter road access. However, on the other hand, the crossing is also a source of disaster, In order to realize increased safety at the crossing of a doorway, especially in the right position at an integrated highway intersection and has been equipped with a Traffic Signaling Tool Keywords: Safety, Train, Square Crossing
\end{abstract}

\begin{abstract}
ABSTRAK
Keselamatan merupakan faktor utama yang menjadi bahan pertimbangan para pengguna jasa untuk memilih moda transportasi yang akan digunakan, baik di darat, laut maupun udara. Perkeretaapian adalah satu kesatuan sistem yang terdiri atas prasarana, sarana, dan sumber daya manusia, serta norma, kriteria, persyaratan, dan prosedur untuk penyelenggaraan transportasi kereta api. SMKP (Sistem Manajemen Keselamatan Perkeretaapian) adalah bagian dari sistem manajemen penyelenggara perkeretaapian secara keseluruhan dalam rangka meningkatkan keselamatan perkeretaapian. Perlintasan sebidang merupakan perpotongan sebidang antara jalur kereta api dengan jalan. Isu yang menonjol pada perlintasan sebidang adalah tingginya angka kecelakaan lalu-lintas antara kendaraan dengan kereta api, terutama pada perlintasan yang tidak dijaga. Kenyataan dimana permasalahan pada perlintasan sebidang selalu kontroversial, dimana pada satu sisi, masyarakat membutuhkan akses jalan yang lebih singkat. Akan tetapi, di sisi lain, perlintasan itu juga menjadi sumber petaka, Dalam rangka mewujudkan peningkatan keselamatan pada perlintasan sebidang berpintu khususnya pada posisi tepat pada persimpangan jalan raya yang terintegrasi dan telah dilengkapi Alat Pemberi Isyarat Lalu lintas.
\end{abstract}

Kata Kunci : Keselamatan, Kereta Api,Perlintasan Sebidang

\section{A. PENDAHULUAN}

Dalam Upaya meningkatkan keselamatan Perkeretaapian. Sebagaimana dijelaskan dalam undang-undang nomor 23 tahun 2007 tentang Perkeretaapian Bab VII Perpotongan Dan Persinggungan Dengan Jalur Kereta Api Dengan Bangunan Lain Bahwa Tidak Memperbolehkan Adanya Perlintasan Sebidang, Kalaupun Ada Maka Harus Ada Penjamin Keselamatan, serta peraturan tentang pemasangan rambu-rambu dijalan raya. Kesalahan tersebut selalu dilimpahkan kepada kereta api yang memang setiap terjadi kecelakaan pada perlintasan sebidang banyaknya korban jiwa berasal dari moda jalan raya. Penyebab kecalakaan tersebut antara lain adalah akibat kelalaian manusia atau penjaga pintu perlintasan ataupun kelalaian pengguna jalan raya yang kurang hati-hati ketika melewati perlintasan sebidang. 
Selain terjadinya kecelakaan pada perlintasan sebidang, terjadi pula kekusutan atau kemacetan kendaraan khususnya pada wilayah perlintasan sebidang yang berada pada persimpangan jalan raya baik yang dilengkapi dengan alat pemberi isyarat lalu lintas maupun yang tidak dilengkapi dengan alat pemberi isyarat lalu lintas. Hal tersebut disebabkan karena ketika pada saat kereta melintas pada perlintasan sebidang dan pintu perlintasan ditutup, alat pemberi isyarat lalu lintas tetap berfungsi sebagaimana biasanya. Namun dengan di tutupnya pintu perlintasan maka kendaraan yang akan melintasi perlintasan sebidang akan terhenti hingga pintu perlintasan terbuka kembali. Hal tersebut mengakibatkan kendaraan yang kan melintasi persimpangan jalan raya yang sejajar dengan jalan rel akan terhenti pula karena terdapat penumpukan kendaraan di depan pintu perlintasan dan tepat di tengah persimpangan.

\section{B. METODOLOGI PENELITIAN}

\section{Pola Pikir Penelitian}

Penelitian ini dilaksanakan di Sekolah Tinggi Transportasi Darat. Secara garis besar pola pikir penelitian dapat dilihat pada Bagan alir di bawah ini :

\section{Metode Pengumpulan Data}

Pengumpulan data adalah langkah pencarian data yang berhubungan dengan penelitian. Data yang diperoleh ini nantinya akan dianalisa untuk diampil kesimpulan dan saran untuk pemecahan permasalahan yang ada. Metode yang digunakan dalam pengumpulan data adalah:

\section{Metode pengumpulan data sekunder}

Data sekunder adalah data yang didapat dari instansi-instansi terkait yang sesuai dengan kebutuhan analisis data berupa:

1. Fasilitas Peralatan Pintu Perlintasan Kereta Api

2. Komponen Peralatan Jalan Rel

3. Komponen Peralatan APILL

4. Komponen Peralatan Yang Akan Diterapkan

\section{Metode Pengumpulan Data Primer}

Data primer adalah data yang diperoleh dengan cara pengamatan langsung di lapangan yang disesuaikan dengan kebutuhan analisis data. Data primer yang diperoleh berupa:

\section{Prinsip kerja Peralatan Pintu Perlintasan Kereta Api}

2. Prinsip kerja Peralatan Jalan Rel

3. Prinsip kerja Peralatan APILL

\section{Metode Pustaka}

Metode pustaka ini dilakukan dengan menggunakan buku-buku panduan sebagai referensi yang berkaitan dengan permasalahan yang ada, sebagai landasaan teori maupun pedoman pelaksanaan praktek dilapangan. 


\section{Teknik Analisis Data}

Sesuai dengan tujuan penelitian yang telah ditetapkan yaitu untuk mengetahui karakteristik dan prinsip kerja fasilitas peralatan pintu perlintasan sebidang, pendeteksi jalan rel, dan alat pemberi isyarat lalulintas (apill), sehingga dapat diintegrasikan guna meningkatkan keselamatan pada perlintasan sebidang yang berada di persimpangan jalan raya dengan dilengkapi alat pemberi isyarat lalulintas. Oleh karena itu peneliti akan menggunakan rancangan penelitian yang bersifat observasi untuk mendiskriptifkan variable yang diteliti dan peneliti juga akan menggunakan rancangan percobaan untuk menguji kehandalan alat pengintegrasian yang akan diterapkan.Adapun untuk penjelasan tentang rancangan penelitian diuraikan sebagai berikut:

\section{Rancangan Penelitian Observasi}

Variable-variabel yang digunakan dalam penelitian observasi, meliputi; Kelengkapan faslitas pintu perlintasan sebidang, Karakteritik dan prinsip kerja peralatan di pintu perlintasan sebidang, Karakteristik dan prinsip kerja pendeteksi kereta api, Karakteristik dan prinsip kerja alat pemberi isyarat lalulintas, dan Karakteristik komponen yang akan digunakan

\section{Rancangan Pembuatan Alat}

Rancangan pembuatan alat ini dimaksudkan untuk membuat alat yang nantinya akan dapat mengintegrasikan antara jalan rel dan alat pemberi isyarat lalu lintas yang berada di perlintasan sebidang berpintu. Rancangan alat yang akan digunakan antara lain; Pembuatan alat pengintegrasi pendeteksi keberadaan kereta api, Pembuatan alat pengintegrasi genta perlintasan, Pembuatan alat pengintegrasian pemberi tanggapan penutupan pintu perlintasan, Pembuatan alat peringatan kedatangan kereta api untuk penjaga pintu perlintasan, Pembuatan peralatan fail safe, Pembuatan alat reset atau pemutusan peralatan pengintegrasi, Pembuatan alat pengintegrasian alat pengintegrasi keberadaan kereta, genta perlintasan, dan tanggapan penutupan pintu perlintasan dengan system kendali alat pemberi isyarat lalu lintas, dan Pembuatan minimal system alat pemberi isyarat lalu lintas yang terintegrasi dengan jalan rel.

\section{Rancangan Percobaan}

Percobaan yang akan digunakan dalam pengujian alat yang akan diterapkan antara lain; Percobaan parsial tiap komponen peralatan, Percobaan fungsi gabungan komponen peralatan, Percobaan kehandalan peralatan, dan Percobaan fail safe kegagalan peralatan

\section{ANALISA DAN PEMBAHASAN}

\section{Kondisi Eksisting Perlintasan Sebidang} Perlengkapan perlintasan sebidang

Sesuai dengan hasil pengamatan dilapangan dapat diketahui bahwa fasilitas perlintasan sebidang telah memenuhi standart minimum perlengkapan yang harus disiapkan di pintu perlintasan sebidang. Perlengkapan tersebut antara lain; Rambu peringatan akan melintasi pintu perlintasan, Rambu stop atau 
berhenti sejenak sebelum melintasai perlintasan kereta api, Pintu perlintasan kereta api, Pos penjaga pintu perlintasan kereta api, Jadwal kereta api, Peralatan pengoperasian pintu perlintasan, Bendera merah, Telepon operasional kereta api (TOKA), Fasilitas tanggap darurat, dan No telepon penting.

\section{Sistem Pengoperasian Perlintasan Sebidang}

Sistem pengoperasian perlintasan sebidang pada lokasi pengamatan memiliki karakteristik yang sama dengan peralatan praktikum perlintasan sebidang yang dimiliki oleh STTD. Sistem pengoperasian dan intergrasinya menggunakan kontaktor dan relay yang di susun sedemikian rupa sehingga dapat menjadi control utama dapat pengoperasian palang pintu perlintasan kereta api. Adapun sistem kontaktor dan relay yang digunakan dapat dilihat pada gambar di atas.

Sedangkan apabila terdapat kasus ada kendaraan yang berhenti atau mogok di tengah perlintasan sebidang, maka petugas penjaga pintu perlintasan wajib memberikan informasi kepada stasiun erdekat bahwa terdapat kendaraan yang terhenti di perlintasan. Sebagai tindakan pengamanan petugas penjaga pintu perlintasan wajib berlari minimal 500m menuju arah datangnya kereta api yang paling awal dan mengibarkan bendera merah di tengah jalan rel sebagai semboyan atau tanda bahwa diperlintasan depan terdapat kendaraan yang terhenti atao mogok. Dengan harapan masinis akan melakukan pengereman sehingga tidak tejadi kecelakaan.

\section{Kondisi Eksisting Alat Pemberi Isyarat Lalu Lintas}

Perlengkapan dalam sistem APILL terdiri dari 3 (tiga) komponen utama yaitu :

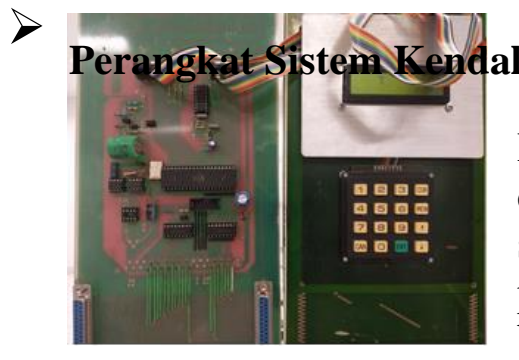

Perangkat ini merupakan perangkat yang digunakan sebagai alat pengendali rencana waktu siklus dari alat pemberi isyarat lalu lintas. Dengan perangkat sistem kendali ini, dapat disesuaikan beberapa scenario pada lampu lintas sesuai dengan

kebutuhan. Perangkat ini terdiri dari microcontroller, inputan sebagai masukan perintah waktu dan output sebagai hasil esekusi dari program yang telah di install di dalam mikrokontroller.Perangkat mikrokontroller sebagaimana dimaksud diatas disusun dengan skema tertentu sehingga mudah untuk dioperasikan.

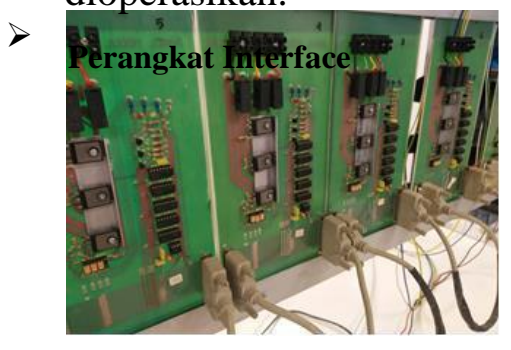

Perangkat interace berfungsi sebagai penerus antara output sistem Kendali dengan perangkat lampu lalu lintas. Perangkat ini terdiri dari kompponen elektronika yang berfungsi untuk merubah signal yang dikeluarkan dari sistem

kendali untuk diteruskan mengontrol relay yang dialiri arus lebih besar sehingga dapat mendrive perangkat lampu lalu lintas. 


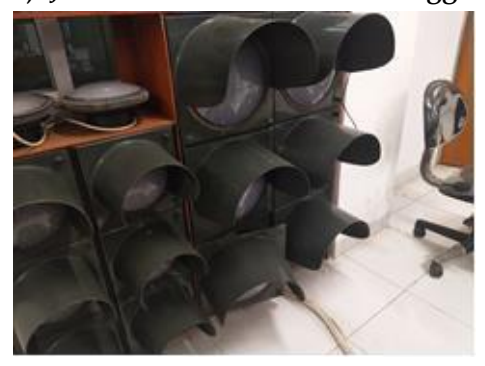

Perangkat lalu lintas merupakan perangkat yang paling akhir atau dapat di sebu sebagai perangkat yang berinteraksi langsung dnegan pengguna jalan. Dalam perangkat ini di operasikan menggunakan sistem kelistrikan dengan arus yang lebih besar, oleh karenanya

untuk dapat mengkontrol perangkat lampu lalu lintas diperlukan interface.

\section{Rencana Pengintegrasian}

\section{1) Rancangan Integrasi Jalan Rel}

Rancangan integrasi jalan rel dirancang dengan mengoptimalkan peralatan yang telah tersedia dan diaplikasikan di lapangan, namun untuk mengintegrasikan peralatan yang telah dilapangan diperlukan skema integrasi tersendiri yang telah dirancang untuk dapat mengintegrasikannya.

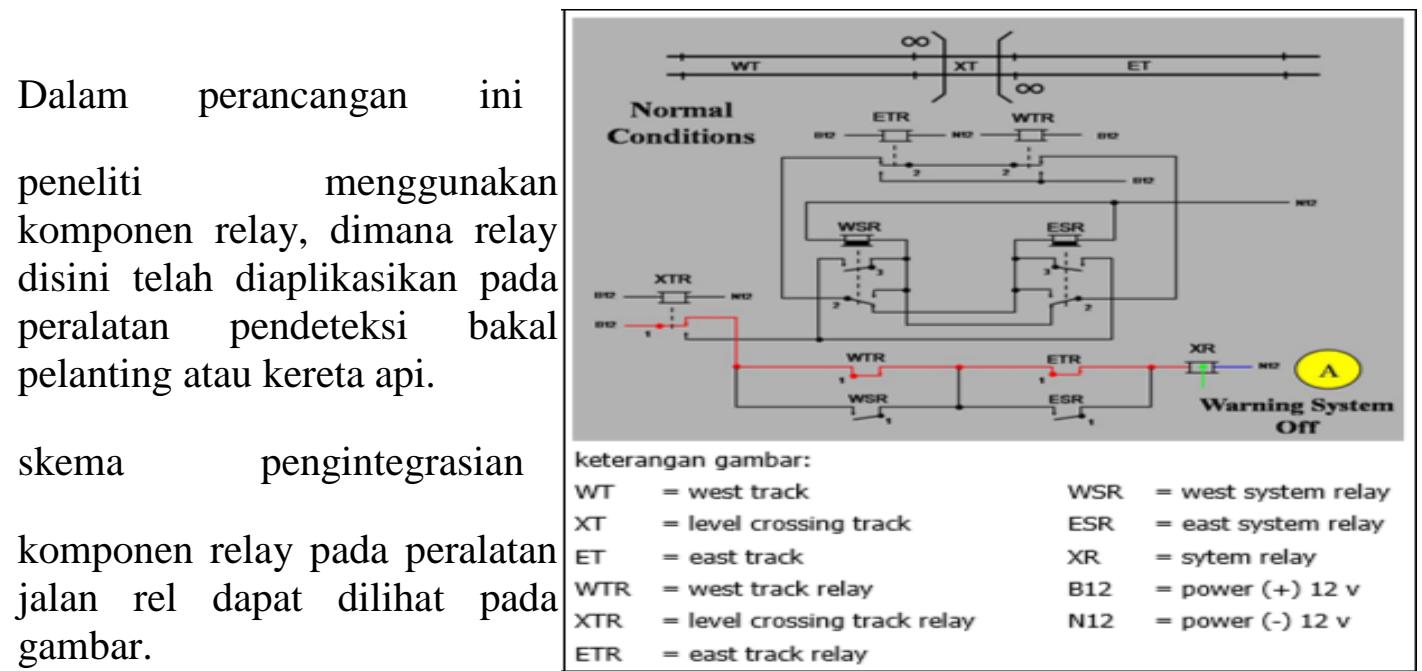

Dari gambar skema diatas dapat diketahui alur relay yang nantinya akan dipasangan dalam pengintegrasian jalan rel telah terkoneksi dengan relay yang terdapat pada jalan rel. namun kondisi normal relay track pada skema adalah posisi off atau tidak terdapat arus listrik dan pada system track circuit menggunakan relay yang terus dialiri arus listrik dan normali relay adalah on. Hal itu dikarenakan system track circuit menjatuhkan relay dan memutuskan arus ke pusat control sehingga pusat control dapat mengetahui keberadaan kereta api. untuk mengintegrasikannya peneliti menggunakan system kebalikan dari track circuit, jadi ketika tidak ada kereta maka relay akan mati dan ketika ada kereta relay akan menyala.

\section{2) Rancangan Integrasi Pintu Perlintasan}


Tidak jauh dengan pengintegrasian jalan rel dan genta, pintu perlintasan juga menggunakan komponen peralatan relay sebagai saklar. Penempatan fungsi relay pada pintu perlintasan disamakan dengan proses awal penutupan pintu

Berdasarkan pengujian gabungan pada table diatas dapat diketahui bahwa dalam 4 hari atau sebanyak 50 kali uji coba tidak terjadi kegagalan sistem. Dengan tidak terdapatnya kegagalan system ini maka untuk pengintegrasian antara pendeteksi kereta api dengan pintu perlintasan dapat dikatakan handal karena $100 \%$ system integrase dapat berjalan dengan sempurna.

\section{FAIL SAFE}

Fail safe merupakan salah satu managemen kesalahan, sehingga apabila terjadi satu kesalahan system, maka system lain akan mencadi backup sehingga tidak akan terjadi kesalahan. Fail safe dengan kata lain dapat diartikan merupakan usaha untuk mengantisipasi apabila terjadi kesalahan pada suatu system, sehingga prosedur tanggap darurat untuk mengatasi masalah tersebut untuk meminimalisir dampak yang terjadi dari masalah yang telah terjadi sehingga system masih dapat dinyatakan aman. Berdasarkan hasil rancangan peralatan pengintegrasian jalan rel dan alat pemberi isyarat lampu lalu lintas dapat beroperasi dengan dua atau lebih indicator yang dapat menjalankan proses pengintegrasian tersebut, dengan system fail safe tersebut maka dapat di simulasikan beberapa kendala yang akan dialami dilapangan dengan diaplikasikannya peralatan pengintegrasi ini. Kendala tersebut antara lain:

1. Tidak berfungsi salah satu peralatan pengintegrasian jalan rel, genta atau pintu perlintasan

2. Tidak berfungsinya semua perlatan pngintegrasian baikjalan rel, genta maupun pintu perlintasan

Tabel Uji Coba Tingkat Kahandalan Aktifasi Manual

\begin{tabular}{|l|l|l|l|l|l|}
\hline NO & UJI & BERHASIL & GAGAL & JUMLAH & $\begin{array}{l}\text { PROSENTASE } \\
\text { BERHASIL }\end{array}$ \\
\hline & & & & & \\
\hline 1 & AKTIFASI MANUAL & 50 & 0 & 50 & $100 \%$ \\
\hline
\end{tabular}


Berdasarkan hasil uji coba diatas diketahui bahwa dari 4 hari uji coba atau sebanyak 50 kali aktifasi secara manual tidak mengalami kendala. Hal tersebut dapat dilihat pada table diatas bahwa tingkat keberhasilan dari hasil uji coba dalah sebesar $100 \%$. Dengan demikian aktifasi secara manual sebagai tindakan pengamanan dapat dilakukan sebagai salah satu upaya pengamanan system pengintegrasian perlintasan sebidang dengan APILL.

3. System pengintegrasian tidak dapat kembali pada system pengintegrasian pada kondisi normal

Tabel Uji Coba Tingkat Kahandalan Reset

\begin{tabular}{|l|l|l|l|l|l|}
\hline NO & UJI & BERHASIL & GAGAL & JUMLAH & $\begin{array}{l}\text { PROSENTASE } \\
\text { BERHASIL }\end{array}$ \\
\hline & & & & & \\
\hline 1 & RESET & 50 & 0 & 50 & $100 \%$ \\
\hline
\end{tabular}

Berdasarkan hasil uji coba diatas diketahui bahwa dari 4 hari uji coba atau sebanyak 50 kali pengoperasian dianggap tidak normal dan dilakukan pengembalian system dengan menggunakan tombol reset sebagai alat bantu tidak mengalami kendala. Hal tersebut dapat dilihat pada table diatas bahwa tingkat keberhasilan dari hasil uji coba dalah sebesar $100 \%$. Dengan demikian fungsi perangkat reset sebagai tindakan pengamanan dapat dilakukan sebagai salah satu upaya pengamanan system pengintegrasian perlintasan sebidang dengan APILL

4. Tidak berfungsinya semua komponen peralatan pengintegrasi

5. Pemadaman lampu.

\section{KESIMPULAN}

Berdasarkan hasil penelitian yang telah dilakukan sebagaimana diuraikan sebelumnya maka dapat disimpulkan :

1. Teknologi/system yang dapat digunakan dalam pengintegrasian perlintasan sebidang dengan APILL adalah menggunakan perangkat yang sudah dioperasikan pada setiap komponen baik APILL, Perlintasan sebidang, 
pendeteksi kereta api maupun genta dimana perangkat tersebut dintegrasikan menggunakan relay dan mikrokontroller sehingga dapat dintegrasikan. System integrasi ini menggunakan Bahasa Logika "NOR" dengan ketentuan minimal 2 (dua) atau lebih perangkat inputan aktif maka system akan aktif,

2. Berdasarkan hasil uji kehandalan dengan tingkat kegagalan kurang dari $5 \%$ baik pada pengujian parsial setiap komponen dan uji gabungan system namun hal tersebut tidak mengurangi tingkat kehandalan system yaitu dapat beroperasi $100 \%$ hal tersebut dikarenakan system integrase ini tidak menuntut

3 (tiga) komponen sebagai input harus dalam kondisi "on" guna mengaktifkan system.

3. Berdasarkan pembahasan system fail safe atau penanganan terhadap kesalahan dan kegagalan peralatan system integrase ini sudah dapat mengamankan sistemnya sendiri dengan di tambahnya system operasi/aktifasi secara manual dan system reset yang memungkinkan operator atau petugas pengjaga perlintasan dapat mengaktifkan secara manual apabila seluru system inputan mengalami kgagalan system dan juga dapat dilakukan reset secara manual untuk mematikan system yang ada.

\section{REFERENSI}

,2007, Undang-Undang Nomor 23 Tentang Perkeretaapian. ,2009, Undang-undang Nomor 22 Tentang Lalu Lintas dan Angkutan Jalan.

,2011, Peraturan Menteri nomor 36 Tentang Perpotongan Dan/Atau Persinggungan Antara Jalur Kereta Api Dengan Bangunan Lain.

, 1993, Keputusan Menteri nomor 62 Tentang Alat Pem
Isyarat Lalu Lintas.
, Modul Teori Dinamika Kedaraan KA, program D-III
perkeretaapian, Sekolah Tinggi Transportasi Darat.

, 1999, Panduan Pengoperasian Panel Gardu Pelintasan, Alstom
Transport B.V
Alstom Transport B. V
1999, Maintenance Manual Level Crossing Barrier System,
Sumardi taufik Sugian, Oetojo Pantja dharma, 2009, Alat Pemberi Isyarat Lalu
lintas (APILL) Portable Sebagai Instrumen Pelengkap Perambuan 
Sementara, Pusat penelitian dan pengembangan Jalan dan jembatan, Bandung

Pratama Uriansah, 2008, Peningkatan Keselamatan Pada Perlintasan Sebidang Dengan Rambu Pendahulu Untuk Perlintasan Sebidang, Sekolah Tingi Tansportasi Darat 